\title{
DOES THE LABELLING RESTRICTION ON CARBOFURAN CONTAINERS HELP PROTECT BURROWING OWLS?
}

\author{
DEANNA TROWSDALE MUTAFOV, 231 Hastings Crescent, Regina, \\ Saskatchewan. S4T 7N8
}

Introduction The Burrowing Owl is designated as a threatened species by the Committee on the Status of Endangered Wildlife in Canada (COSEWIC). ${ }^{3}$ The current 1992 population counts from the private stewardship program Operation Burrowing $O w 1$ indicate that numbers are continuing to decline rapidly. If conditions causing the decline are not reversed, the Burrowing Owl is likely to become endangered. The reasons for its decline are uncertain but habitat loss, pesticide spraying, vehicle collisions, and natural predation have been documented.

The Burrowing Owl nests in badger, fox, or gopher burrows on pastures, road sides and even in cultivated fields. Its diet consists of small rodents and insects, primarily grasshoppers. Therefore, due to the nesting and diet requirements of the Burrowing Owl, this species is potentially susceptible to sprays meant for grasshopper control. In years of high grasshopper infestations, the spraying of insecticides increases dramatically.

In 1986, a study was carried out to determine the impact of several commercial pesticide sprays, including Carbofuran (Furadan 480F), on the reproductive success of Burrowing Owls in Saskatchewan. ${ }^{2}$ Carbofuran is an insecticide used primarily for grasshopper control. The mechanism of toxic action of this chemical is the inhibition of the enzyme acetylcholinesterase, activity of which is essential for nervous system function in insects, birds and mammals. It was shown that when Carbofuran was sprayed over nest burrows, it had a significant impact on the survival and reproductive success of Burrowing Owls. In fact, according to the study, burrows sprayed directly with Carbofuran showed an 83 percent reduction in the number of young and an 82 percent reduction in nest success. In several instances, adult owls were sprayed with Carbofuran and low site re-occupancy was recorded the following year. ${ }^{1,2}$

From the results of the study, it was recommended that the use of Carbofuran be suspended in the breeding range of the Burrowing Owl. A second option was to make mandatory buffer zones for spraying around Burrowing Owl nest sites. Through compromise, a restriction was established by Agriculture Canada in 1989 which prohibits the use of Carbofuran within $250 \mathrm{~m}$ of Burrowing Owl nests. This action was implemented as a supplementary label on the Carbofuran container. The restriction was also advertised through various communication 


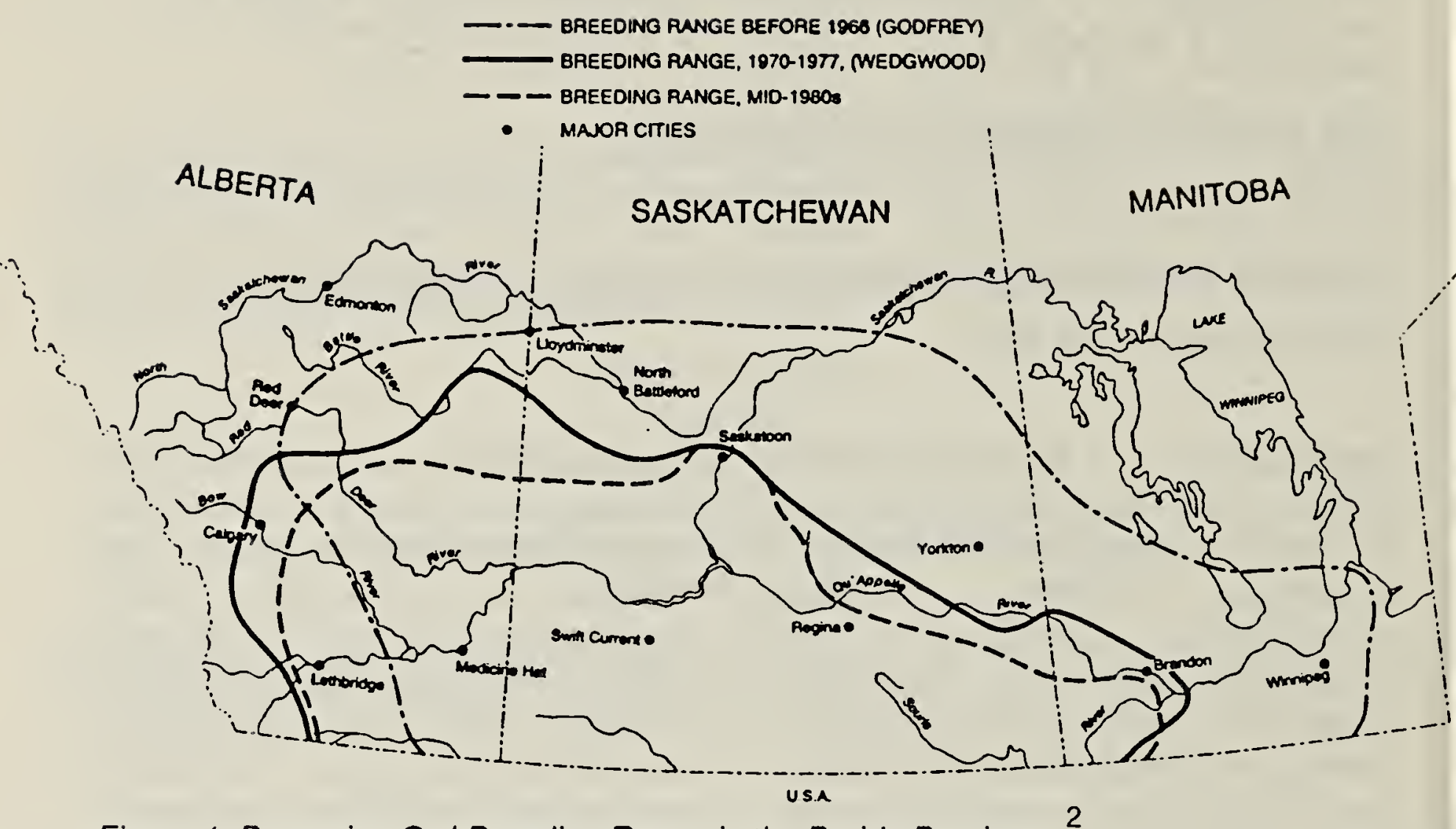

Figure 1. Burrowing Owl Breeding Range in the Prairie Provinces. ${ }^{2}$

channels such as radio, television, newspaper, mail and agricultural dealerships. However, the effectiveness of this labelling and advertising had not been evaluated up to this point.

Methods and Results A product user awareness questionnaire on the insecticide Carbofuran was conducted by telephone during the months of October and November 1991. A random stratified sample of 100 Saskatchewan landowners within the current range of the Burrowing Owl was used to conduct the survey (Figure 1). These landowners were not Operation Burrowing Owl members. Land locations, including the quarter, section, township, range and meridian, were chosen by using a random numbers table. The survey questions were used to assess the usage of Carbofuran and its labelling restrictions with respect to the
Burrowing Owl. Questions also included were those assessing general knowledge of the Burrowing Owl. Following are the results of the survey.

From the 100 landowners contacted, 35 had used Carbofuran at some time in the previous five years. Two had used it for all of the five years. Sixteen had used it during the two years when the restriction was widely publicized. Almost all Carbofuran users sprayed for grasshoppers with only a few using it for flea beetles.

Of the 100 respondents, 82 were familiar with Burrowing Owls, and 62 were familiar with the program Operation Burrowing Owl. Sixty-two could identify a Burrowing Owl, and $18 \mathrm{knew}$ of Burrowing Owls in their fields or adjacent to their fields in 1991. On a more sombre note, not 
one person involved in the survey knew of the exact restriction associated with the application of Carbofuran with respect to the Burrowing Owl, although 31 were partly aware of some restriction, or of the toxicity associated with Carbofuran.

Of the 35 landowners who had used Carbofuran in the previous five years, 83 percent were familiar with Burrowing Owls; 74 percent had heard of Operation Burrowing Owl; 71 percent could identify a Burrowing Owl, and 43 percent have, or once had, Burrowing Owls on their property. However, only 6 percent of the 35 Carbofuran users could recall looking at the current label restriction on the container but could not remember the exact restriction. Only 4 percent of the users were partly aware of any risks to the Burrowing Owl from Carbofuran and only 26 percent said that they recalled some form of advertising on the Carbofuran restriction.

Discussion It is obvious from the results of the survey that there is a good general awareness of the Burrowing Owl in southern Saskatchewan. Due to the program Operation Burrowing Owl, many landowners are aware that the Burrowing $\mathrm{OWl}$ is facing serious threats to its survival. Also apparent, however, is the general lack of awareness on the use of Carbofuran with respect to the Burrowing Owl. The restriction had been in effect for two years at the time of the survey, and had been very well publicized through various channels. Yet not one of the randomly chosen landowners knew of the exact restriction. Very few of the Carbofuran users appeared to be knowledgeable about the risks that this insecticide posed to the Burrowing Owl or to wildlife in general.
Although a small random sample size was used for the survey, the results indicate an underlying problem with the level of public awareness of the insecticide Carbofuran and its effects on the Burrowing Owl.

Although not the only factor having an impact on the survival of the Burrowing Owl, Carbofuran certainly appears to pose a greater risk than other insecticides do to this species. ${ }^{1,2}$ Fox emphasizes that it is very important that landowners and managers are made aware of the hazards that Carbofuran and other insecticides pose on this bird. The results of this survey show that many landowners are still not aware of these hazards. It is therefore concluded that the current labelling restriction is ineffective. The Saskatchewan Natural History Society calls for a re-evaluation of this labelling restriction and for further consideration to be given to the removal of this chemical from the market.

The complete report on this study is available from Dale Hjertaas (7872892).

Appreciation is extended to Paul C. James, Dale Hjertaas and Carol Bjorklund.

1. FOX, G.A., and P.C. JAMES. 1987. Effects of some insecticides on productivity of Burrowing Owls. Blue Jay 45:65-71.

2. FOX, G.A., P. MINEAU and P.C. JAMES. 1989. Technical report series no. 72. Canadian Wildlife Service, Ottawa.

3. WEDGWOOD, J.A. 1978. Status report on Burrowing Owls in Canada. Canadian Wildlife Service for Committee on the Status of Endangered Species in Canada, Saskatoon. 